\title{
Microstructure, mechanical properties, and cutting performance of TiAlSiN multilayer coatings prepared by HiPIMS
}

\author{
Guodong $\mathrm{Li}^{\mathrm{a}}$, Jianfei Sun ${ }^{\mathrm{a}}$, Ye Xu $\mathrm{Xu}^{\mathrm{a}, *}$, Yi Xu ${ }^{\mathrm{b}, \mathrm{c}}$, Jiabin $\mathrm{Gu}^{\mathrm{a}}$, Lei Wang ${ }^{\mathrm{a}}$, Kai Huang ${ }^{\mathrm{a}}$, Kuan Liu ${ }^{\mathrm{a}}$, \\ Liuhe $\mathrm{Li}^{\mathrm{a}}$,* \\ ${ }^{a}$ School of Mechanical Engineering and Automation, Beihang University, Beijing, PR China \\ ${ }^{\mathrm{b}}$ School of Engineering Science, University of Chinese Academy of Science, Beijing, PR China \\ ${ }^{\mathrm{c}}$ Institute of Mechanics, Chinese Academy of Sciences, Beijing, PR China
}

\section{A R T I C L E I N F O}

\section{Keywords:}

TiAlSiN

HiPIMS

Inconel 718

Film toughness

Cutting tools

\begin{abstract}
A B S T R A C T
To explore mechanical properties of multilayer TiAlSiN coatings deposited on turning tools and their cutting performance against Inconel 718, TiAlSiN coatings with five different multilayer configurations, including single layer TiAlSiN-A (with higher adhesion strength), single layer TiAlSiN-B (with higher hardness), bilayer, fourlayer, and eight-layer, were deposited using high power impulse magnetron sputtering (HiPIMS). The microstructure, chemical composition, hardness, adhesion, toughness and surface roughness of those coatings are measured and the cutting performance against Inconel 718 is analyzed. It is demonstrated that the multilayer structure results in an increase of both toughness and compressive stress of TiAlSiN coatings, and the one with eight-layer configuration shows the highest toughness among the five coatings. The results of the cutting experiment showed that eight layer coatings have maximum life while the TiAlSiN-A has minimum. This improvement of multilayer structure is believed to be due to the increasing toughness, which alleviates the damage caused by the frequent impact of Inconel 718 hard particles during cutting. This study also shows there is a negative correlation between spalling area of flank surface and adhesion of coatings.
\end{abstract}

\section{Introduction}

Inconel 718 is a type of superalloys extensively used in the aircraft and nuclear industry because it is capable of maintaining excellent mechanical properties and high thermal resistance under extreme conditions. However, it is also characterized by high work-hardening, appearance of abrasive carbide particles, built-up edge formation and low thermal conductivity [1-4]. Considerable researches and development efforts are directed worldwide; however, machining of Inconel 718 remained a difficult problem. One of the promising solutions is to protect the surface of cutting tools with superhard coatings [5-8]. To optimize the cutting performance of those protective coatings, previous studies have explored several factors of effective coatings including microstructure [9], composition [10], power supply type [11], deposition parameters and others [12-14].

Because of their high hardness, high temperature stability, and the ability to endure abrasion, TiAlN coatings have been extensively researched in cutting Inconel 718 [5,8,15,16]. More recently, by addting silicon, researchers have found out that TiAlSiN possesses better mechanical properties and thermal stability than TiAlN [17,18], which is believed to be resulted from the nanocomposite structure in TiAlSiN where crystalline nc-TiAlN phases are wrapped in amorphous a-Si3N4 phase at nanometer scale [17]. O. Durand-Drouhin [19] found that alloying of silicon into TiAlN single layer led to a significant increase of hardness attributed to the reduction of grain size, as described by the Hall Petch effect. Derflinger, V H et al. [20] studied the oxidation resistance, wear behavior, and hardness of TiAlSiN coatings, which are improved by adding silicon into TiAlN coatings. But until now, there are very few studies investigating the cutting performance of TiAlSiN coated cutting tools against Inconel 718.

On the other hand, creating multilayer structure is one of the methods of improving mechanical properties of existing coatings. Coatings with multilayer structure have been found to have high temperature stability [21], greater cutting performance [7], higher adhesion and lower residual stress [22,23]. For example, E. Vogli [24] and his colleagues succeed in making Ti/TiAlN-multilayer coatings, and their study shows the multilayer coating with the thickest ceramic layers has the highest hardness, lowest wear coefficient and lowest compressive residual stress. Sui Xudong compared monolayer and bilayer coatings of TiAlN/TiAlSiN. and found that premature spalling

\footnotetext{
* Corresponding authors.

E-mail addresses: ye.xu@buaa.edu.cn (Y. Xu), liliuhe@buaa.edu.cn (L. Li).
} 
Table 1

Technical parameters of the TiAlSiN coatings.

\begin{tabular}{|c|c|c|c|c|c|}
\hline Sample no. & Number of layers $(n)$ & Modulation Period $(\Lambda) / \mu \mathrm{m}$ & modulation ratio (A:B) & Thickness/ $\mu \mathrm{m}$ & Bias-voltage/V \\
\hline \#A & 1 & / & / & $2.3 \pm 0.05$ & -150 \\
\hline \#B & 1 & / & / & $2.0 \pm 0.05$ & -270 \\
\hline \#M2 & 2 & 2.100 & $1: 2$ & $2.1 \pm 0.05$ & $-150 /-270$ \\
\hline \#M4 & 4 & 1.050 & $1: 2$ & $2.1 \pm 0.05$ & $-150 /-270 / 150 /-270$ \\
\hline \#M8 & 8 & 0.525 & $1: 2$ & $2.1 \pm 0.05$ & $-150 / \ldots /-270$ \\
\hline
\end{tabular}
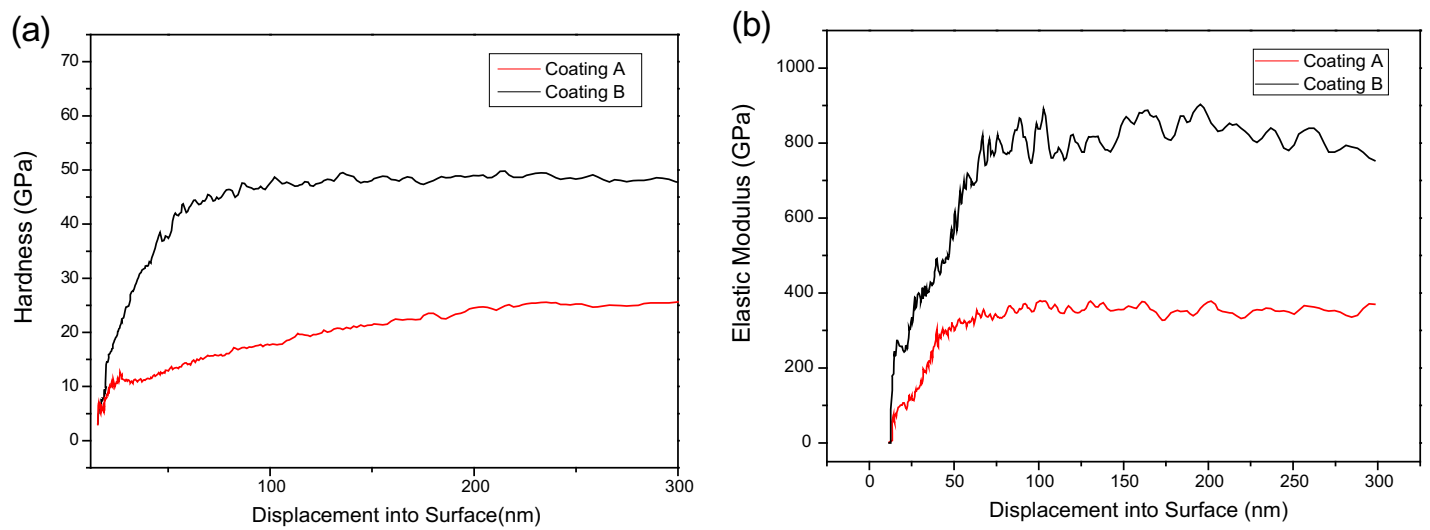

Fig.1. (a): The hardness of coating A and coating B; (b) The elastic modulus of coating A and coating B.

(a)

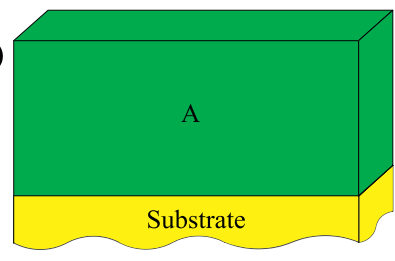

(b)

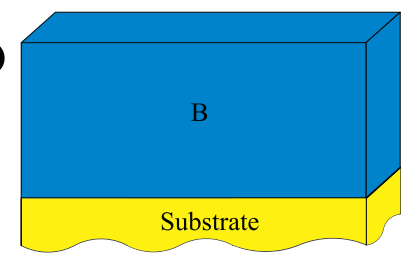

(c)

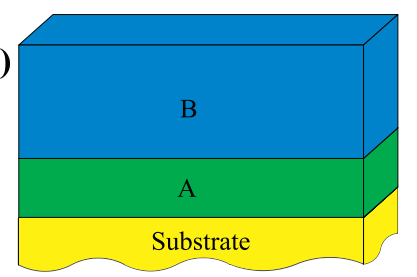

(d)

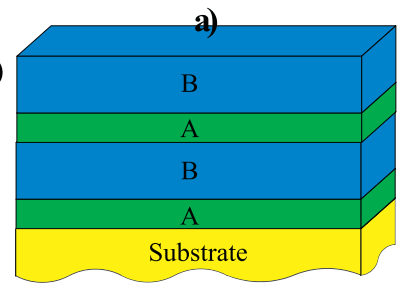

(e)

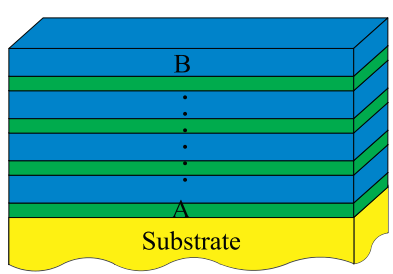

Fig. 2. Schematic diagram of TiAlSiN coatings: (a) single layer \#A (high-adhesion film); (b) single layer \#B (high-hardness film); (c) bilayer coating \#M2; (d) Four layer coating \#M4; (e) eight layer coating \#M8.

Table 2

Chemical composition of Inconel $718\left(\mathrm{~W}_{\mathrm{t}} \%\right)$.

\begin{tabular}{llllllllll}
\hline $\mathrm{Ni}$ & $\mathrm{Cr}$ & $\mathrm{Nb}$ & $\mathrm{Mo}$ & $\mathrm{Ti}$ & $\mathrm{C}$ & $\mathrm{Si}$ & $\mathrm{Mn}$ & $\mathrm{B}$ & $\mathrm{Fe}$ \\
\hline 51.75 & 17 & 5.15 & 2.93 & 1.07 & 0.042 & 0.21 & 0.03 & 0.006 & Last \\
\hline
\end{tabular}

problem is alleviated by forming the TiAlN/TiAlSiN bilayer structure [17]. In most of those previous studies, multilayer coatings are consisted of two materials with quite different chemical compositions [25], and therefore usually deposited alternatively using at least two targets. As a result, the preparation process is complicated and costly especially for nano-multilayer coatings with hundreds of layers [26,27].

In this work, we prepared a series of TiAlSiN coatings consisting of layers with the same composition but alternating high and low hardness by varying the parameters of high power impulse magnetron sputtering (HiPIMS) used in preparing our coatings. We studied the cutting
Table 3

Composition of TiAlSiN coatings.

\begin{tabular}{lllll}
\hline Sample no. & \multicolumn{2}{l}{ Element concentration (at.\%) } \\
\cline { 2 - 5 } & $\mathrm{Ti}$ & $\mathrm{Al}$ & $\mathrm{Si}$ & $\mathrm{N}$ \\
\hline \#A & 34 & 25 & 12 & 29 \\
\#B & 38 & 22 & 12 & 28 \\
\#M2 & 36 & 24 & 12 & 28 \\
\#M4 & 35 & 24 & 13 & 28 \\
\#M8 & 36 & 23 & 12 & 28 \\
\hline
\end{tabular}

performance of those TiAlSiN coatings and also conducted a systematic investigation of the microstructures and mechanical properties of those coatings. We have identified the toughness of the coatings as a key materials property that is responsible for improving the cutting performance of multilayer TiAlSiN coatings. 

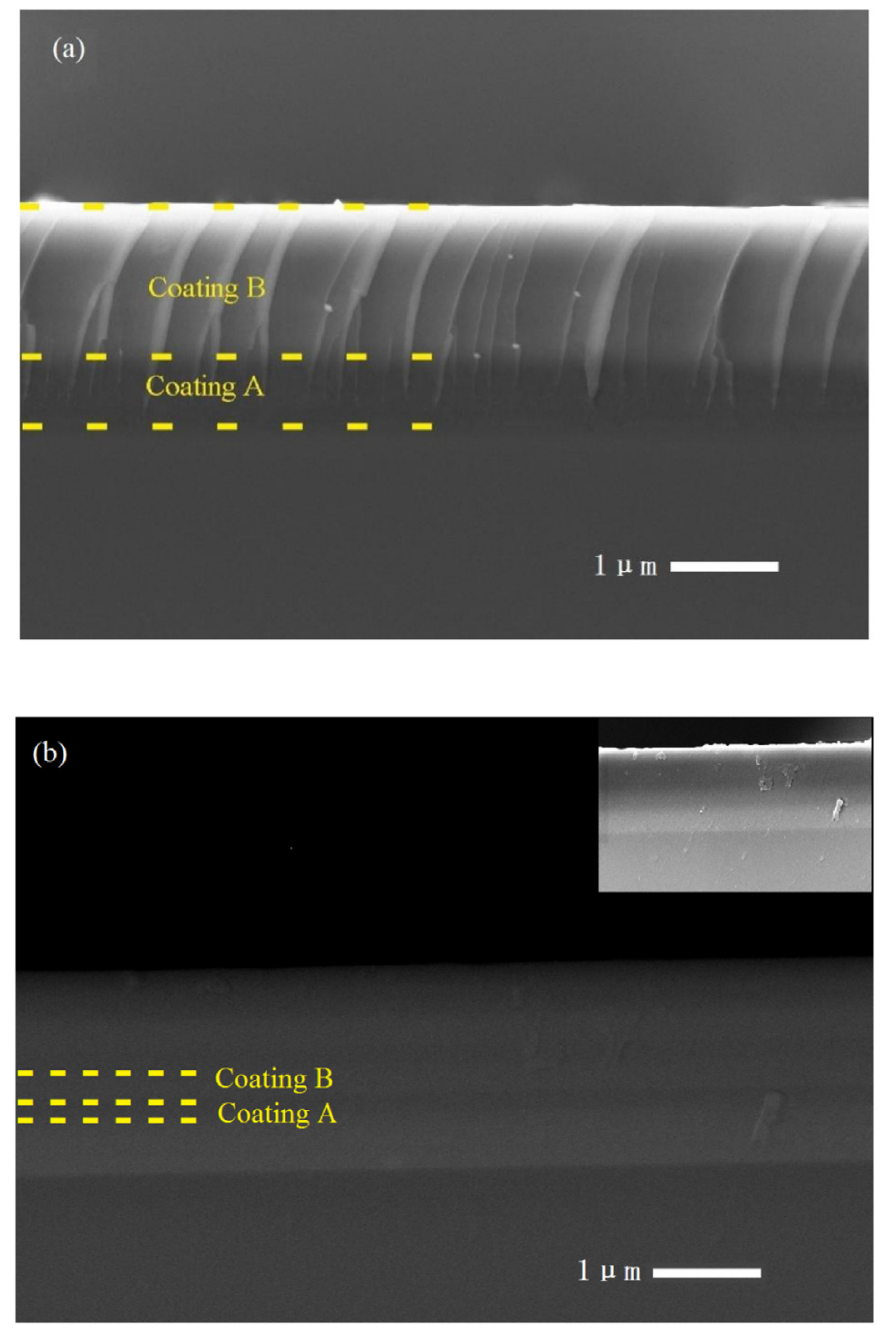

Fig.3. (a) Cross-section SEM images of Bi-layer TiAlSiN coating (SED), the toothed shape is caused by the cracking of silicon; (b) cross-section SEM images of eight-multilayer TiAlSiN coating. The main image is showed by backscattered detector (BSD); The thumbnail image at top right corner is showed by secondary electron detector (SED).

\section{Experimental details}

\subsection{Coating preparation}

All TiAlSiN nanocomposite coatings were deposited on the uncoated WC-CO tool inserts (YG8, CNMG120408) by HiPIMS method. After mechanically polished and ultrasonically cleaned, all substrates were cleaned by glow discharge for $30 \mathrm{~min}$ at $1.5 \mathrm{~Pa}$ Ar pressure and $800 \mathrm{~V}$ substrate bias voltage in order to ensure the maximum degree of cleanliness of the surface. Based on our previous studies, two types of coatings are deposited by HiPIMS using different bias voltage that coating A shows low hardness while coating B shows high hardness. Unlike the previous studies [28], we use nitrogen-ion implantation method to treat the substrate instead of depositing transition layer, which might leading to different nucleation and growth of grains could influence coatings properties. During the coating preparation, deposition temperature is controlled in $200^{\circ} \mathrm{C}$, the vacuum chamber was evacuated to a base pressure of $2 * 10^{-3} \mathrm{~Pa}$ and the deposition was carried out in a mixture of high purity argon (99.999\%) and nitrogen (99.999\%) gases within a hybrid ion implantation and deposition apparatus equipped with $\mathrm{Ti}_{0.64} \mathrm{Al}_{0.3} \mathrm{Si}_{0.06}$ sputtering target which is in the form of rectangular plates mounted vertically. The pulse width and frequency of HiPIMS are $400 \mu \mathrm{s}$ and $50 \mathrm{~Hz}$, respectively. For depositing (a)

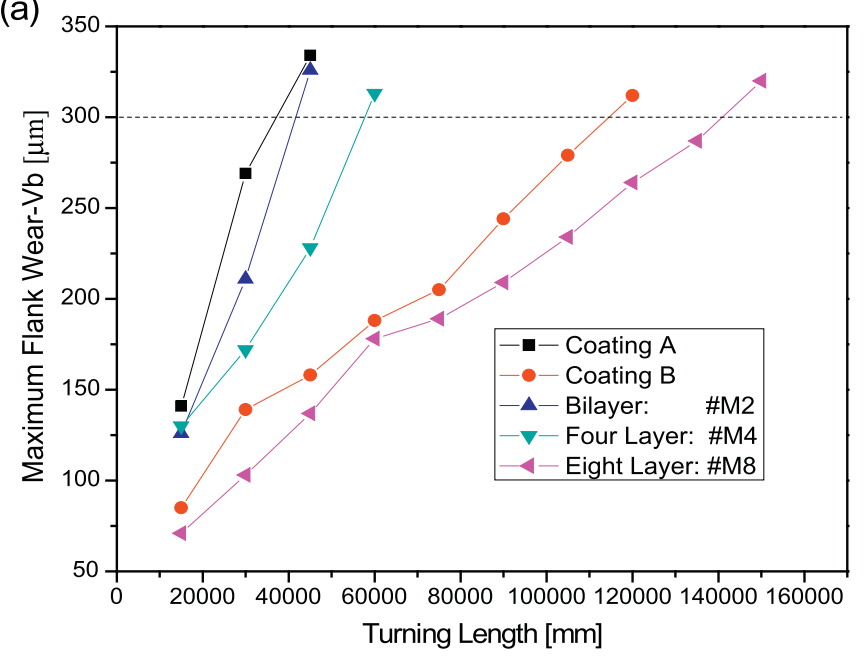

(b)

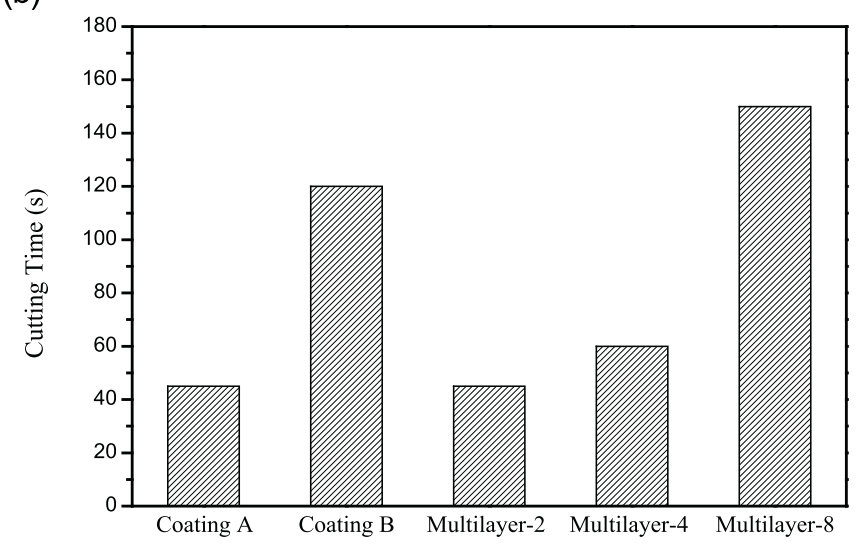

Fig. 4. (a) Tool flank wear Vb curve versus cutting length of different coated tools; (b) tools life of flank wear above $300 \mu \mathrm{m}$ of different coated tools.

coating A, bias voltage, supply voltage, and pressure are kept at $150 \mathrm{~V}$, $850 \mathrm{~V}$, and $0.8 \mathrm{~Pa}$, respectively, while those parameters were $270 \mathrm{~V}$, $900 \mathrm{~V}$ and $1 \mathrm{~Pa}$ for depositing coating B. In the consideration of keeping high hardness of coatings, modulation ratio of coating A to coating B is selected as 1:2 in preparing multilayer coatings. The resulting twolayer, four-layer, and eight-layer coatings are designated as \#M2, \#M4, and \#M8, respectively. The key deposition parameters, the thickness of each layer and structural model for each coating are summarized in Table 1 and Fig. 2. (See Fig.1.)

\subsection{Cutting experiments}

The Inconel 718 round bars $(50 \mathrm{~mm}$ in diameter and $200 \mathrm{~mm}$ in length) were prepared as the work material. Before each test, the workpiece was prepared by removing an approximately 1.5 -mm-thick layer from the outside surface to eliminate any effect of workpiece surface inhomogeneities on the experimental results. The chemical composition of the workpieces is given in Table 2. Dry turning tests were conducted on a CGK6125A CNC lathe Machine. The cutting depth $V_{p}$ is $1 \mathrm{~mm}$ and the feed rate $f_{a}$ is $0.1 \mathrm{~mm} / \mathrm{r}$. A high cutting speed of $60 \mathrm{~m} / \mathrm{min}$ is selected in this study. The tool's flank wear $\left(V_{b}\right)$ is an important parameter for evaluating the tool's failure. As is shown in Fig. 5, the tool flank wear $\left(V_{b}\right)$ is defined as the average width of the middle position in flank's banded wear zone. The tool flank wear $\left(V_{b}\right)$ is observed every $15 \mathrm{~s}$ under a standard optical microscope to monitor the wear. The tool life criterion was set to be a maximum flank wear of $300 \mu \mathrm{m}$. 

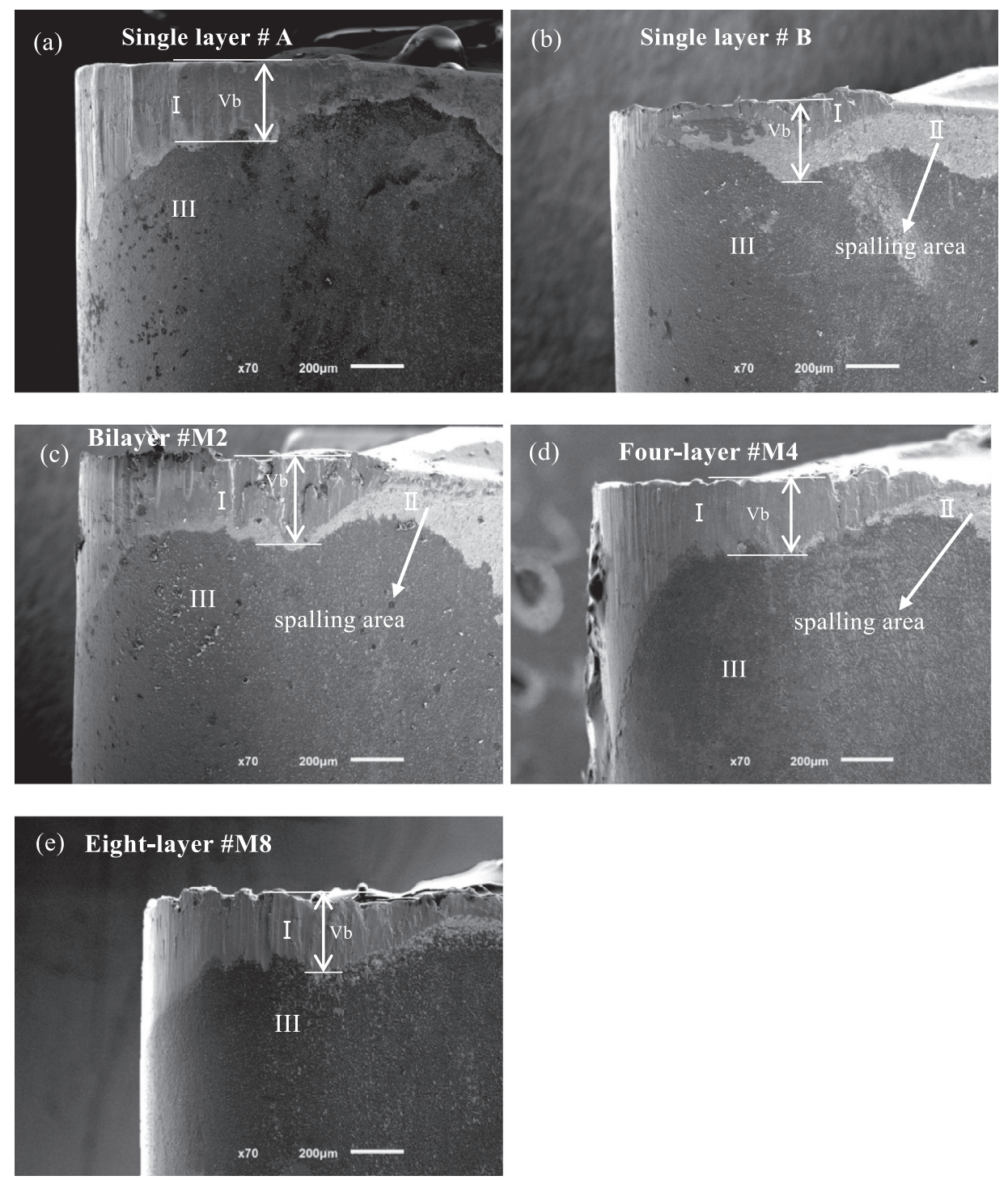

Fig. 5. Tool flank wear forms of different coatings, region I is built-up edge area, region II is spalling area, region III is coating area. (a) single layer \#A; (b) single layer \#B; (c) bilayer \#M2; (d) four-layer \#M4; (e) eight-layer \#M8.

\subsection{Characterization}

All the TiAlSiN coatings were characterized by using a series of analytical techniques. Energy dispersive spectroscopy (EDS) and SEM (JSM 6010LA) were used to acquire the element content, cross-sectional morphology, tool flank wear $\left(V_{b}\right)$ and thickness of coatings. In order to analyze the phase and crystal structures, X-ray diffractometry (XRD) with $\mathrm{CuK \alpha}$ radiation in grazing incidence mode $\left(2^{\circ}\right)$ was used. The surface roughness and morphology of coatings were analyzed by Atomic force microscopy (AFM, Veeco Dimension icon with Scan Asyst). Nanoindentation tester (Nano-Indentor G200, Agilent) with a load precision of $50 \mathrm{nN}$ was used to measure nano-hardness and modulus of the coatings. The continuous stiffness method (CSM) [29] was used to obtain displacement-hardness values from initial to final indentation depth. The average hardness was calculated with hardnessdisplacement curves collected at the indentation depth of 100-300 nm (the depth was within 1/10 thickness of the TiAlSiN coating and the data were stable) at five random sites, and the maximum applied force is $80 \mathrm{mN}$. The adhesion strength was tested with a scratch tester (MFT4000) at a loading speed of $100 \mathrm{~N} / \mathrm{min}$ and a scratch length of $5 \mathrm{~mm}$.

\section{Results and discussion}

\subsection{Cutting experimental results}

The cutting performance of TiAlSiN coated tools were summarized in Fig. 4. The tool flank wear $V_{b}$ versus the turning length is plotted in Fig. 4(a) for five TiAlSiN coatings with different multilayer structures. As is shown in the plot, most coatings consisting of softer coating A layer, \#M2 and \#M4 exhibit faster wear rate than the harder coating B. However, the \#M8 coating with eight alternating layers show even slower wear rate than coating B, suggesting an improved cutting performance. Besides, the Fig. 4(b) indicates that the tools life will increase as the number of layers increases.

Worn surfaces $\left(\mathrm{V}_{\mathrm{b} \text { max }}=0.3\right)$ were investigated with SEM and EDS in order to further study the wear pattern of five coatings, which showed in Fig. 5. It is observed that the composition within region I is $\mathrm{Ni}, \mathrm{Fe}, \mathrm{Cr}$ and $\mathrm{C}$, among which $\mathrm{Ni}, \mathrm{Cr}, \mathrm{Fe}$ are believed to come from Inconel 718, which implies that regionI is the built-up edge area. Region II has relative high contents of $\mathrm{W}$ and $\mathrm{C}$ which comes from the cement carbide substrate. It suggests that the coating at this location has been spalling during the cutting process. Region III mainly involves elements including $\mathrm{Ti}, \mathrm{Al}, \mathrm{Si}$ and $\mathrm{N}$ which suggests that at least part of 

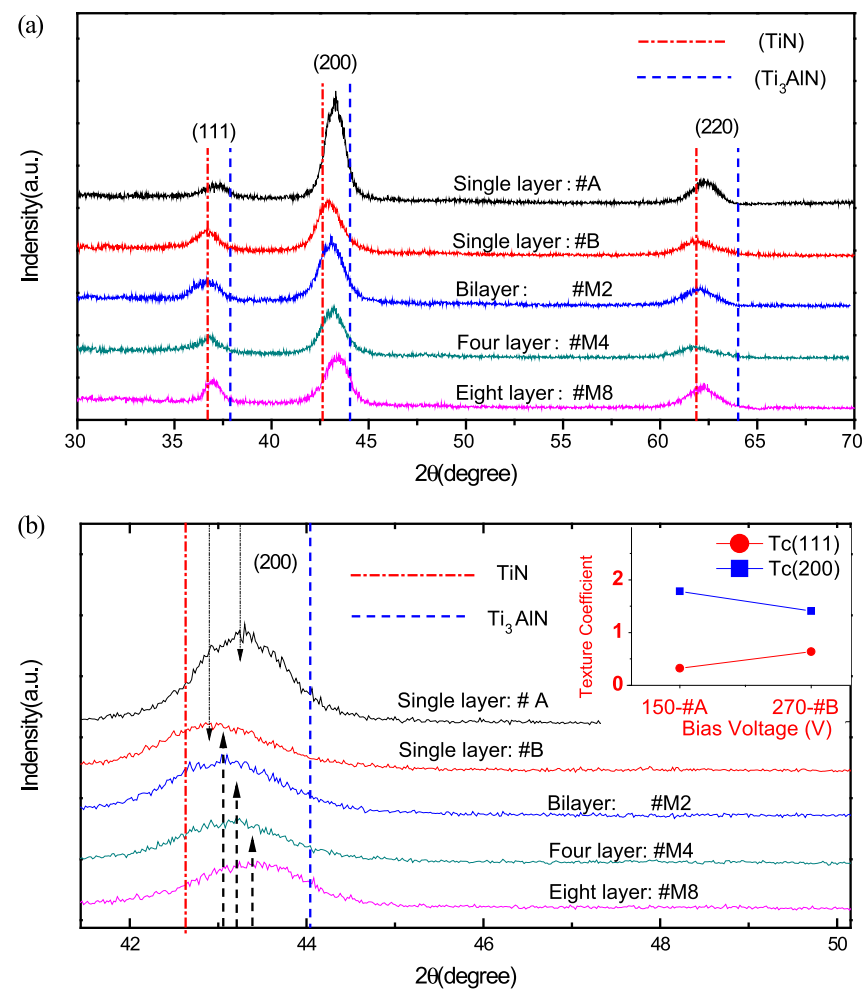

Fig. 6. (a) XRD patterns of TiAlSiN coatings (b) zoom of (200) peak for identifying the shift, the upper right is the (111) and (200) texture coefficient (Tc) of coating A and coating B.

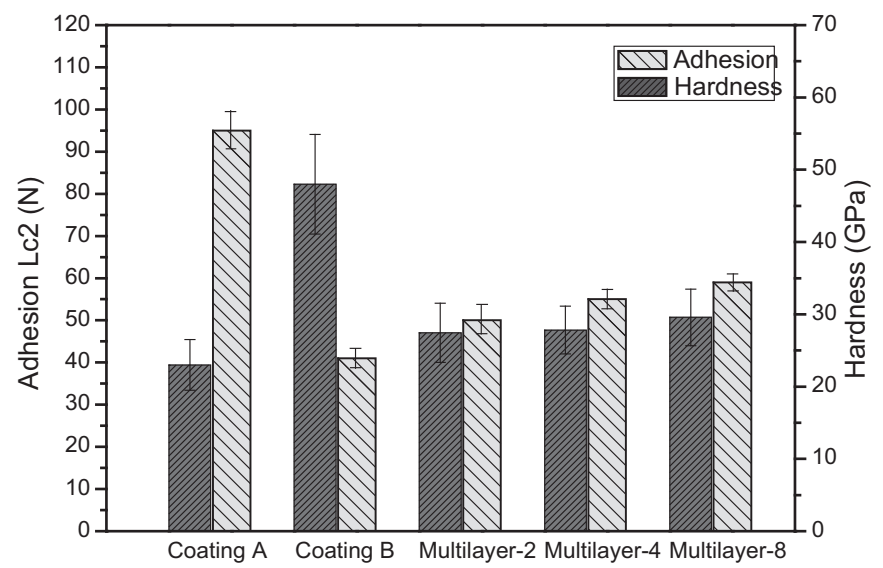

Fig. 7. Hardness and adhesion of TiAlSiN coatings with different microstructure.

the coatings at this position is remain intact.

As is shown in Fig. 4, eight-layer coatings exhibit the maximum service life and relatively smaller spalling area, while coating A has shortest lifespan among five coatings. There are various characters of coating, including microstructure, hardness, adhesion, toughness, etc., that can impact the cutting performance. To study the origin of different cutting performance, microstructure and mechanical properties of those five coatings are further analyzed below.

\subsection{Structure characterization}

The composition of single layered and multilayered TiAlSiN coatings was studied by EDS. To lessen the EDS detection error, each date of the element concentration is the average value of five dates acquired. As is shown in Table 3, coating B has slightly more Ti but less Al, Si and
$\mathrm{N}$ than coating A. Those differences in element concentration are likely due to the change of atom mobility, diffusion, and re-sputtering. When bias voltage increased, re-sputtering plays a dominate role in the element concentration change [30]. Also the increase of Ti content is mainly because that light $\mathrm{Al}$ atoms are easier re-sputtered by impinging ions with high energy than heavier Ti atoms. For multilayer coatings, the content of $\mathrm{Ti}$ and $\mathrm{Al}$ is between coating $\mathrm{A}$ and coating $\mathrm{B}$. As the number of layers increase, elements ratio has little change due to the fact that ratio of coating A and B keeps almost constant. Fig. 3 shows the SEM fracture cross section images of TiAlSiN multilayer coatings on silicon substrate, the multilayer structure can be identified clearly.

Fig. 6 presents the XRD patterns of investigated single layers and multilayers coatings.As shown in Fig. 6, we found no AlN phases in the $\mathrm{XRD}$ results due to high ratio of $\mathrm{Ti} / \mathrm{Al}$ [10], which indicate that $\mathrm{Al}$ element is likely to exist in the form of $\mathrm{Ti}_{3} \mathrm{AlN}$ compound as the $\mathrm{NaCl}$ type crystal structure. As is shown in Fig. 6, all three peaks are corresponding to the (111), (200), (220) planes can be identified as TiN or $\mathrm{Ti}_{3} \mathrm{AlN}$. The absence of silicon related peak suggests that silicon exists as a-Si $\mathrm{N}_{\mathrm{y}}$ phase or be incorporated in the fcc lattice, or both. These preferential orientations are in agreement with JCPDF\#87-0633 (TiN) and JCPDF\#37-1140 ( $\left.\mathrm{Ti}_{3} \mathrm{AlN}\right)$ from ICCD cards. The (200) plane has the lowest surface energy in the fcc lattice of NaCl-type crystal structure is well known $[32,33]$. The texture coefficient (Tc) of planes (111) and (200) is observed by using the inverse pole figures method. As is shown in Fig. 6(b), the preferred orientation of both coating A and B is (200) plane, and coating A shows stronger (200) planes than coating B. Whereas, coating B shows stronger (111) planes than coating A. This is because that the higher bias voltage used to prepare coating $\mathrm{B}$ has a stronger effect on re-sputtering (200) plane. Since the ratio of coating A and $\mathrm{B}$ is constant, the preferential crystal orientation of multilayer coatings is also (200) plane, same as the one in the single layer coating B.

Fig. 6(b) shows a zoom-out view of the XRD results near the (200) peak. For single layer, the diffraction peak of coating A has higher angle $(2 \theta=43.25)$ than coating B $(2 \theta=42.92)$. For multilayer coatings, as the number of layers increases, the diffraction peak of $\mathrm{Ti}_{3} \mathrm{AlN}(200)$ had evidently moved towards a higher-angle than that in coating B. Usually, the shift is elated to change of the element content or residual stress (macro-stress). Coating A have more Al content than coating B according to EDS results in Table 3, and therefore more TiN phase were replaced by $\mathrm{Ti}_{3} \mathrm{AlN}$ phase $[28,34]$, As a result, it is reasonable that, coating A shows higher angle in peak (200). For multi-layer structure, however, the element contents have little change in M2, M4 and M8 according to the EDS measurement. Therefore, the higher residual compressive stress is probably causing the shift of peak (200) in higher angle as the number of layers increases (see Fig. 6(b)). This is also supported by many studies [24,35] arguing that the multilayer structure has an influence on residual stress of coatings. Besides, compressive stress of coatings is related to the toughness, which will be further elaborated in the later part of the paper.

The full-width-half-maximum (FWHM) of the single layer coating B's (200) peak is also shown to be wider than that of coating A (Fig. 6b). It is well known that the broadening of peaks is usually caused by the decrease of grain size. Sundgren [36] also proposed that more surface defects would generated with pulsing bias increased which result in a fine grain size. Because the time-average energy flux increased as the bias increased, more surface defects on the growing film are produced by the higher energy of incident ions. Also in Fig. 6(b), this broadening could be attributed to the decrease in grain size because of the bombardment of higher energy ions during the growth of coating B. The grain sizes are calculated using Debye-Scherrer formula [37] and listed in Table 4, the value of grain size is the average value of all layers. The grain size of the multilayer coatings was found to be between those of coating A and B but has a trend of increasing as the number of layers increases. 
(a)

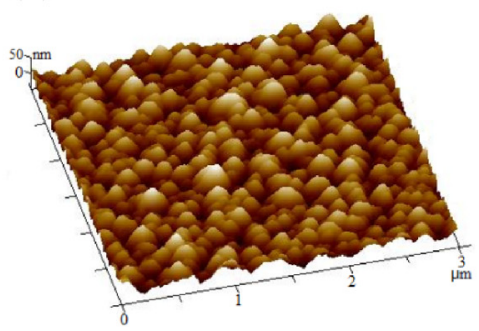

(b)

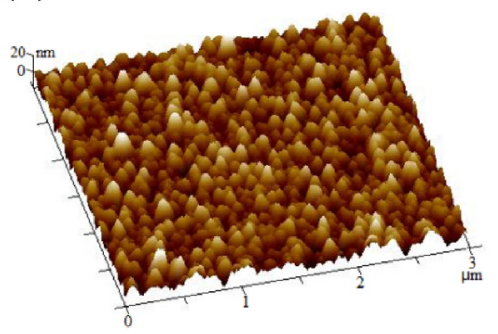

(e) (c)

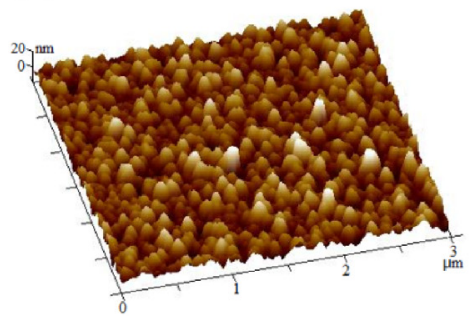

(d)

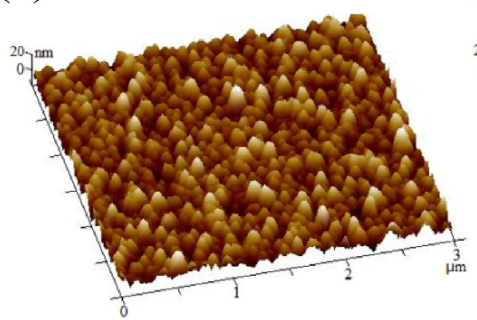

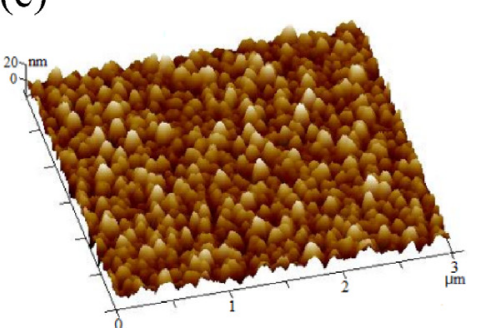

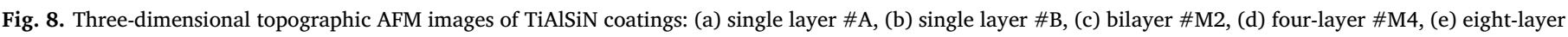
\#M8.

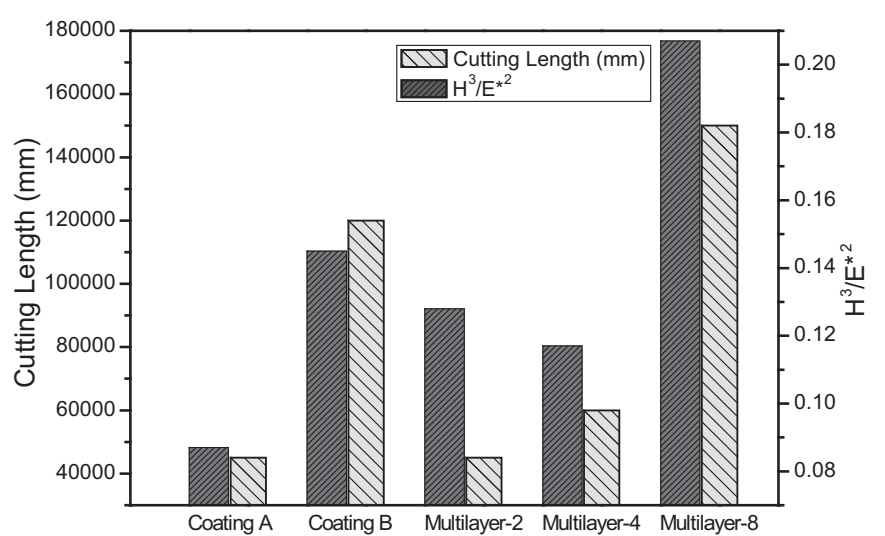

Fig. 9. Cutting length and $\mathrm{H}^{3} / \mathrm{E}^{*^{2}}$ of TiAlSiN coatings with different microstructure, and shows a positive correlation between cutting length and $\mathrm{H}^{3} / \mathrm{E}^{* 2}$.

\subsection{Mechanical properties}

The mechanical properties of coatings, including hardness, elastic modulus, $\mathrm{H}^{3} / \mathrm{E}^{* 2}$ ratio, adhesion, as well as grain size and surface roughness all have great influence on cutting performance of Inconel 718. The hardness of the Coating B (48Gpa) is the highest mainly due to the minimum grain size among all coatings [38]. Comparing with Coating B, multilayer coatings show lower hardness for two reasons. In one point because of the softer layer (A). When the ratio of the indentation depth to the film thickness (D/t) [39] exceeds a critical value, the measured hardness $\mathrm{H}$ would be influenced by the substrate material. Another reason may due to the stress relief of alternate soft-hard multilayer [40]. In alternate soft-hard multilayer architecture, the stress of the hard layer may be released from the soft layer [41] and cause the hardness decline. For multilayer coatings (\#M2, \#M4, \#M8), the hardness increased slightly as the number of layers increases. It could be attributed to the increasing number of interfaces in the multilayer structure. For multilayer coatings, dislocation mobility could occur within each individual layer, but it difficult to penetrate the interface unless there are enough driving force [44]. As a result, dislocation mobility can be inhibited by the coating interfaces. When the same loading force applied to the coating, the coating with more interfaces has less dislocation mobility, resulting a bit higher hardness.

We also investigated the toughness of the coatings by calculating the $\mathrm{H}^{3} / \mathrm{E}^{* 2}$ ratio from the nanoindentation measurements. The $\mathrm{H}^{3} / \mathrm{E}^{* 2}$ ratio, called the plastic resistance parameter, is an indicator of the coating's resistance to plastic flow [42], where $\mathrm{H}$ and $\mathrm{E}^{*}$ are the hardness and effective modulus of the coating. $E^{*}$ could be further expressed as $\mathrm{E}^{*}=\mathrm{E} /\left(1-v^{2}\right)$, where $\mathrm{E}$ is the Young's modulus, and $\mathrm{v}$ is the Poisson ratio $(\sim 0.25)[18]$. According to the literatures $[32,43,44]$, the
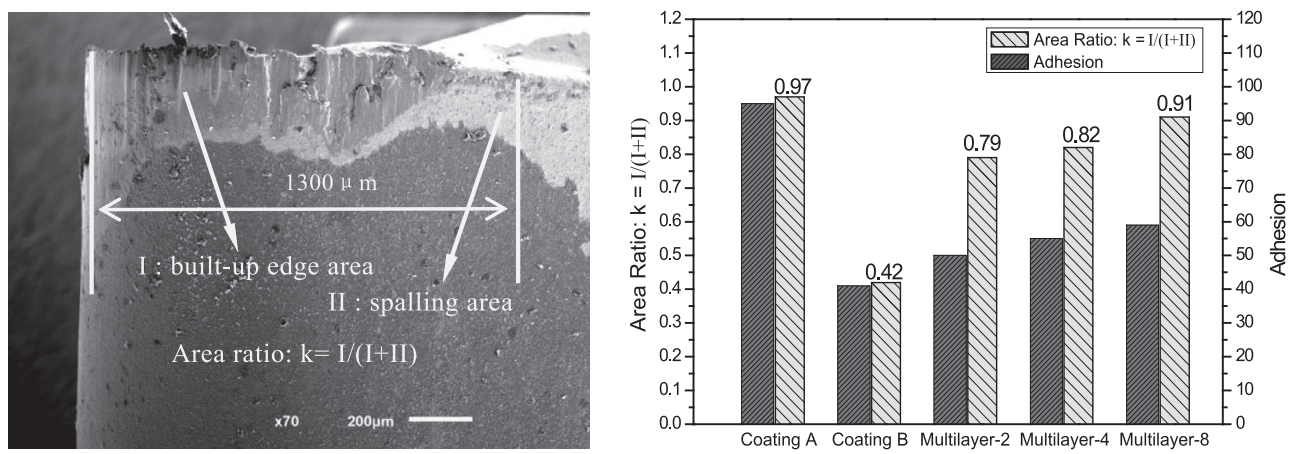

Fig. 10. (a) The schematic of area ratio: $k$. $k$ represents the area ratio of built-up edge area I to sum of whole wear area (I + II) within range of $1300 \mu \mathrm{m}$ from tool tip to flank surface. (b) Adhesion and $\mathrm{k}$ of TiAlSiN coatings. 
Table 4

Morphological and mechanical properties of TiAlSiN coatings.

\begin{tabular}{|c|c|c|c|c|c|c|}
\hline Coatings & $\mathrm{Lc}(\mathrm{N})$ & $\mathrm{H}(\mathrm{GPa})$ & $E^{*}(\mathrm{GPa})$ & $\mathrm{H}^{3} / \mathrm{E}^{* 2}$ & Grain size (nm) & Surface roughness (nm) \\
\hline Single layer \#A & $95 \pm 9$ & $23.1 \pm 3.5$ & $373 \pm 29$ & 0.087 & $55 \pm 0.5$ & $12.2 \pm 1.4$ \\
\hline Single layer \#B & $41 \pm 5$ & $47.9 \pm 7.0$ & $871 \pm 66$ & 0.145 & $31 \pm 0.8$ & $3.9 \pm 0.8$ \\
\hline Bilayer \#M2 & $50 \pm 7$ & $27.5 \pm 4.1$ & $427 \pm 30$ & 0.113 & $43 \pm 0.4$ & $4.1 \pm 1.1$ \\
\hline Four layer \#M4 & $55 \pm 7$ & $27.8 \pm 3.3$ & $410 \pm 27$ & 0.128 & $39 \pm 0.2$ & $3.9 \pm 0.9$ \\
\hline Eight layer \#M8 & $59 \pm 8$ & $29.6 \pm 3.9$ & $353 \pm 23$ & 0.207 & $37 \pm 0.6$ & $3.9 \pm 1.2$ \\
\hline
\end{tabular}

toughness of the coating can be represented by $\mathrm{H}^{3} / \mathrm{E}^{*}$ ratio. As is shown by Table 4 , the coating $B$ exhibited higher $\mathrm{H}^{3} / \mathrm{E}^{* 2}$ ratio than coating A. It is also shown that the toughness of the coatings improves with the number of layers in the multilayer structure, with the highest value of $\mathrm{H}^{3} / \mathrm{E}^{* 2}$ to be found in the multilayer coating \#M8. We hypothesize that the increasing number of layers lead to the increased area of interfaces which helps prevent or decrease crack propagation or deflection, and correspondingly improves coatings' toughness. Another possible explanation is that coatings \#M8 have maximum residual stress according XRD results, and high residual stress would contribute to producing less and shorter crack that can improve coatings' toughness $\left(\mathrm{H}^{3} / \mathrm{E}^{* 2}\right)$. This result is compatible with the findings from Wu et al. $[45,46]$.

The adhesion strength between coating and substrate, tested by scratch tester, is shown in Fig. 7. The $\mathrm{L}_{\mathrm{c} 2}$ is associated with the start of chipping failure extending from the arc tensile cracks, indicating adhesive failure between the coating and the substrate. The single layer $\mathrm{A}$ has the best adhesion strength with the $\mathrm{L}_{\mathrm{c} 2}$ value of about $95 \mathrm{~N}$ while the minimum of critical load was observed in single layer B. For multilayer, the critical load increases with the increasing layer number and reaches the maximum value in \#M8. This is also associated to the fact that there are a plenty of interfaces and compress stress that made crack bifurcate, deflect or stop growing. In addition, thinner period made the dislocations which among the layers difficult to move, hence, those will require a higher shear stress to move and spread across the whole coating and generate the delaminating of the multilayer coating $[35,47,48]$. As a result, the adhesion increased slightly as layers increased.

Analyses of the surface morphology of the coatings were performed by means of AFM observation. AFM images of TiAlSiN single layer A and B, multilayer \#M2, \#M4 and \#M8 are shown in Fig. 8. The values of the roughness are listed in Table 4. It can be clearly seen that the single layer B have a relatively smoother morphology than the single layer A. This result likely due to the increased energy of ion bombardment would cause large amount of grain boundary which can refine grain size, and hence smoothing the surface [49]. This corresponds well to the tendency observed as results of XRD analysis. No significant difference in roughness is found among the multilayer coatings with different number of layers since the surface roughness of multilayers is essentially determined by the same top layer (coating B).

\subsection{Discussion}

Comparing coating B and \#M8, coating B has higher hardness while it has shorter tool life than \#M8, it can be concluded that hardness is not the only factor in determining the service life of coatings.

By analyzing all data obtained in measurements, it clearly shows a positive correlation between toughness and tool life in Fig. 9. In the cutting process, the Inconel 718 can precipitate a mass of hard phase at elevated temperature. Consequently, the coating suffers intensively alternating shock load generated by machining, and the toughness of the coatings became the key factor under the serious condition.

Fig. 10(a) shows the relation between area ratio (k) of spalling area II and built-up edge area I, which $\mathrm{k}$ represents the area ratio of built-up edge area I to sum of whole wear area (I + II) within range of $1300 \mu \mathrm{m}$ from tool tip to flank surface. It shows the area ratio (k) and the adhesion of coatings are in positive correlation in Fig. 10(b). In those coatings, the coating B and \#M2 even appear a large area of spalling caused by low adhesion as shown in Fig. 5. On the contrary, owing to their high adhesion, coating A and \#M8 have almost no area II. This could be because mass hard phase produces severe friction on flank surface in the cutting process, thus the spalling occurs in the coatings with low adhesion.

\section{Conclusion}

In this study, the cutting experiments were conducted on nickelbase superalloy Inconel 718 by a series of TiAlSiN coated tools, including high-hardness coating, high-adhesion coating, and bilayer, four-layer, eight-layer of coatings deposited by above high-hardness and high-adhesion coatings alternately and repeatedly by HiPIMS. The effects of different coatings to cutting performance, the coatings' structure and properties are explored in detail. And the conclusion can be reached as the following.

(1) Residual stress of coatings grows with layers increasing. The toughness of the coatings improved with the multiplication of layer structure, which may be because that increasing layers lead to increased interfaces which helps prevent or decrease crack propagation or deflection and correspondingly improves coatings' toughness $\left(\mathrm{H}^{3} / \mathrm{E}^{* 2}\right)$. In addition, hardness and adhesion slightly increased with the increasing of layers while surface roughness changed insignificantly.

(2) Toughness has a great influence on tool life. During the cutting process of Inconel 718, the great mass of hard phases with strong impact load on coating surface, so toughness is the vital factor affecting tool life. To sun up, \#M8 shows the best toughness and longest tool life.

(3) Cutting experiments of TiAlSiN coating tools have shown that adhesion abrasion and coating spalling are the main damage forms of the coatings. Adhesion of coatings is found related with spalling area (II), with adhesion increased, spalling area reduced, and it can be achieved by prepared multilayer coatings.

\section{Acknowledgements}

The works were supported by National Science and Technology Major Project [04: 2014ZX04012012].

\section{References}

[1] A. Bhatt, H. Attia, R. Vargas, V. Thomson, Wear mechanisms of WC coated and uncoated tools in finish turning of Inconel 718, Tribol. Int. 43 (2010) 1113-1121.

[2] Z.F. Liu, L. Peng, Z.D. Lv, Study on tool wear of indexable coating inserts for turning Inconel 718, Adv. Mater. Res. 583 (2012) 259-262.

[3] D.G. Thakur, B. Ramamoorthy, L. Vijayaraghavan, Study on the machinability characteristics of superalloy Inconel 718 during high speed turning, Mater. Des. 30 (2009) 1718-1725.

[4] L.J. He, J.H. Xu, H.H. Su, Y. Chen, Turning of cast Inconel 718 with coated carbide and whisker reinforced ceramic tools, Mater. Sci. Forum 770 (2013) 136-140.

[5] I. Ucun, K. Aslantas, B. Gokce, F. Bedir, Effect of tool coating materials on surface roughness in micromachining of Inconel 718 super alloy, Proc. Inst. Mech. Eng. B J. Eng. Manuf. 228 (2014) 1550-1562.

[6] İ. Ucun, K. Aslantas, F. Bedir, The performance of DLC-coated and uncoated ultrafine carbide tools in micromilling of Inconel 718, Precis. Eng. 41 (2015) 135-144. 
[7] G.S. Fox-Rabinovich, B.D. Beake, K. Yamamoto, M.H. Aguirre, S.C. Veldhuis, G. Dosbaeva, A. Elfizy, A. Biksa, L.S. Shuster, Structure, properties and wear performance of nano-multilayered TiAlCrSiYN/TiAlCrN coatings during machining of Ni-based aerospace superalloys, Surf. Coat. Technol. 204 (2010) 3698-3706.

[8] Z. Hao, Y. Fan, J. Lin, Z. Yu, Wear characteristics and wear control method of PVDcoated carbide tool in turning Inconel 718, Int. J. Adv. Manuf. Technol. 78 (2015) 1329-1336.

[9] A. Rizzo, L. Mirenghi, M. Massaro, U. Galietti, L. Capodieci, R. Terzi, L. Tapfer, D. Valerini, Improved properties of TiAlN coatings through the multilayer structure, Surf. Coat. Technol. 235( (2013) 475-483.

[10] Q. Ma, L. Li, Y. Xu, X. Ma, Y. Xu, H. Liu, Effect of Ti content on the microstructure and mechanical properties of TiAlSiN nanocomposite coatings, Int. J. Refract. Met. Hard Mater. 59( (2016) 114-120.

[11] H. Hoche, C. Pusch, R. Riedel, C. Fasel, A. Klein, Properties of SiCN coatings for high temperature applications - comparison of RF-, DC- and HPPMS-sputtering, Surf. Coat. Technol. 205 (Supplement 1) (2010) S21-S27.

[12] I. Ucun, K. Aslantas, F. Bedir, An experimental investigation of the effect of coating material on tool wear in micro milling of Inconel 718 super alloy, Wear 300 (2013) 8-19.

[13] E. Zhang, Q. Chen, Q. Wang, B. Huang, propertIes and cutting performance of TiAlSiN coating prepared by cathode arc ion plating, Surf. Rev. Lett. 23 (2016) 1650055.

[14] D.G. Thakur, B. Ramamoorthy, L. Vijayaraghavan, Some investigations on high speed dry machining of aerospace material Inconel 718 using multicoated carbide inserts, Mater. Manuf. Process. 27 (2012) 1066-1072.

[15] W. Akhtar, J. Sun, W. Chen, Effect of machining parameters on surface integrity in high speed milling of super alloy GH4169/Inconel 718, Mater. Manuf. Process. 31 (2016) 620-627.

[16] G. Akhyar Ibrahim, C.H. Che Haron, J. Abdul Ghani, A.Y.M. Said, M.Z. Abu Yazid, Performance of PVD-coated carbide tools when turning Inconel 718 in dry machining, Adv. Mech. Eng. 3 (2015) 790975.

[17] X. Sui, G. Li, X. Qin, H. Yu, X. Zhou, K. Wang, Q. Wang, Relationship of microstructure, mechanical properties and titanium cutting performance of TiAlN/ TiAlSiN composite coated tool, Ceram. Int. 42 (2016) 7524-7532.

[18] Y. Chang, S. Yang, W. Wu, Y. Kuo, J. Lee, C. Wang, Mechanical properties of gradient and multilayered TiAlSiN hard coatings, Thin Solid Films 517 (2009) 4934-4937.

[19] O. Durand-Drouhin, A.E. Santana, A. Karimi, V.H. Derflinger, A. Schütze, Mechanical properties and failure modes of TiAl(Si)N single and multilayer thin films, Surf. Coat. Technol. 163-164 (2003) 260-266.

[20] V.H. Derflinger, A. Schütze, M. Ante, Mechanical and structural properties of various alloyed TiAlN-based hard coatings, Surf. Coat. Technol. 200 (2006) 4693-4700.

[21] Y. Chang, S. Yang, High temperature oxidation behavior of multicomponent TiAlSiN coatings, Thin Solid Films 518 (2010) S34-S37.

[22] H. Zhao, J. Zhang, Z. Wang, P. Lin, Z. Wang, Adhesion and residual stress of plasma sprayed alumina-titania coatings, J. Adhes. Sci. Technol. 29 (2015) 991-1001.

[23] J.Y. Yan, Y.D. Sun, D.J. Li, M.Y. Liu, L. Dong, M. Cao, C.K. Gao, N. Wang, X.Y. Deng, H.Q. Gu, R.X. Wan, X. Sun, High-temperature stability of TiAlN/TiB 2 multilayers grown on $\mathrm{Al}_{2} \mathrm{O}_{3}$ substrates using IBAD, Surf. Coat. Technol. 229( (2013) 105-108.

[24] E. Vogli, W. Tillmann, U. Selvadurai-Lassl, G. Fischer, J. Herper, Influence of Ti/ TiAlN-multilayer designs on their residual stresses and mechanical properties, Appl. Surf. Sci. 257 (2011) 8550-8557.

[25] J.S. Koehler, Attempt to design a strong solid, Phys. Rev. B 2 (1970) 547-551.

[26] U. Selvadurai, W. Tillmann, G. Fischer, T. Sprute, The influence of multilayer design on residual stress gradients in Ti/TiAlN systems, Mater. Sci. Forum 768-769 (2013) 264-271.
[27] T. Liang, M. Ashton, K. Choudhary, D. Zhang, A.F. Fonseca, B.C. Revard, R.G. Hennig, S.R. Phillpot, S.B. Sinnott, Properties of Ti/TiC interfaces from molecular dynamics simulations, J. Phys. Chem. C 120 (2016) 12530-12538.

[28] Q. Ma, L. Li, Y. Xu, J. Gu, L. Wang, Y. Xu, Effect of bias voltage on TiAlSiN nanocomposite coatings deposited by HiPIMS, Appl. Surf. Sci. 392( (2017) 826-833.

[29] G. Hochstetter, A. Jimenez, J.L. Loubet, Strain-rate effects on hardness of glassy polymers in the nanoscale range. Comparison between quasi-static and continuous stiffness measurements, J. Macromol. Sci., Part B: Phys. 38 (2006) 681-692.

[30] Y. Lv, L. Ji, X. Liu, H. Li, H. Zhou, J. Chen, Influence of substrate bias voltage on structure and properties of the CrAlN films deposited by unbalanced magnetron sputtering, Appl. Surf. Sci. 258 (2012) 3864-3870.

[32] R. Shuangquan, H. Jun, W. Hongjun, T. Canxin, G. Liping, F. Dejun, Effects of bias voltage on the structure and mechanical properties of thick $\mathrm{CrN}$ coatings deposited by mid-frequency magnetron sputtering, Plasma Sci. Technol. 11 (2009) 38-41.

[33] H. Du, J. Xiong, H. Zhao, Y. Wu, W. Wan, L. Wang, Structure and properties of TiAlLaN films deposited at various bias voltages, Appl. Surf. Sci. 292( (2014) 688-694.

[34] L. Ipaz, J.C. Caicedo, J. Esteve, F.J. Espinoza-Beltran, G. Zambrano, Improvement of mechanical and tribological properties in steel surfaces by using titanium-aluminum/titanium-aluminum nitride multilayered system, Appl. Surf. Sci. 258 (2012) 3805-3814.

[35] J.E. Sundgren, Structure and properties of TiN coatings, Thin Solid Films 128 (1985) 21-44.

[36] J.I. Langford, X-ray diffraction procedures for polycrystalline and amorphous materials by H. P. Klug and L. E. Alexander, J. Appl. Crystallogr. 8 (1975) 573-574.

[37] M. Diserens, J. Patscheider, F. Lévy, Improving the properties of titanium nitride by incorporation of silicon, Surf. Coat. Technol. 108-109 (1998) 241-246.

[38] B.J. Nsson, S. Hogmark, Hardness measurements of thin films, Thin Solid Films 114 (1984) 257-269.

[39] Y. Lin, A.W. Zia, Z. Zhou, P.W. Shum, K.Y. Li, Development of diamond-like carbon (DLC) coatings with alternate soft and hard multilayer architecture for enhancing wear performance at high contact stress, Surf. Coat. Technol. 320 (2017) 7-12.

[40] Z. Xu, Y.J. Zheng, F. Jiang, Y.X. Leng, H. Sun, N. Huang, The microstructure and mechanical properties of multilayer diamond-like carbon films with different modulation ratios, Appl. Surf. Sci. 264( (2013) 207-212.

[41] P.H. Mayrhofer, C. Mitterer, J. Musil, Structure-property relationships in singleand dual-phase nanocrystalline hard coatings, Surf. Coat. Technol. 174-175 (2003) 725-731.

[42] W. Tillmann, J. Herper, I.A. Laemmerhirt, Tribological comparison of different surface topographies coated with chromium aluminum nitride, Materialwiss Werkst. 44 (2013) 730-735.

[43] M. Stoiber, C. Mitterer, T. Schoeberl, E. Badisch, G. Fontalvo, R. Kullmer, Nanocomposite coatings within the system Ti-B-N deposited by plasma assisted chemical vapor deposition, J. Vac. Sci. Technol., B: Microelectron. Nanometer Struct. 21 (2003) 1084

[44] Y. Bao, C. Liu, J. Huang, Effects of residual stresses on strength and toughness of particle-reinforced TiN $/ \mathrm{Si}_{3} \mathrm{~N}_{4}$ composite: theoretical investigation and FEM simulation, Mater. Sci. Eng. A 434 (2006) 250-258.

[45] S. Wu, G. Zhang, S. Wu, Y. Su, Residual stress and fracture toughness of PIRAC titanium nitride coatings, Surf. Rev. Lett. 24 (2017) 1750056.

[46] J.C. Caicedo, C. Amaya, L. Yate, O. Nos, M.E. Gomez, P. Prieto, Hard coating performance enhancement by using $[\mathrm{Ti} / \mathrm{TiN}] \mathrm{n},[\mathrm{Zr} / \mathrm{ZrN}] \mathrm{n}$ and $[\mathrm{TiN} / \mathrm{ZrN}] \mathrm{n}$ multilayer system, Mater. Sci. Eng. B 171 (2010) 56-61.

[47] S. Tien, J. Duh, Effect of heat treatment on mechanical properties and microstructure of CrN/AlN multilayer coatings, Thin Solid Films 494 (2006) 173-178.

[48] X.L. Peng, Z.H. Barber, T.W. Clyne, Surface roughness of diamond-like carbon films prepared using various techniques, Surf. Coat. Technol. 138 (2001) 23-32. 